\begin{tabular}{|lcccccc|}
\hline $\begin{array}{l}\text { Social Work/Maatskaplike } \\
\text { http://socialwork.journals.ac.za/pub }\end{array}$ & Werk & $\begin{array}{c}\text { Vol 51 No 3; Issue } \\
\text { doi:http://dx.doi.org/51-3-458 }\end{array}$ & 8 \\
\hline
\end{tabular}

POSITIVE LIVING STRATEGIES THAT CAN BE LEARNED FROM STUDIES ON NEAR-DEATH EXPERIENCES AND LIFETHREATENING ILLNESSES

Madhu Kasiram, Penny Sartori

This article addresses the two related issues of near-death experience and life-threatening illness with a view to helping survivors and helping professionals appreciate how to make sense of the experience whilst considering future living and future service provision. The article is based on two related research studies, citing literature from different disciplines of nursing, women's health, spirituality and near death. This research was undertaken in the light of these experiences affecting so many aspects of life and living. The need to "dialogue with death" (Easwaran, 2008: Foreword) and life-threatening illness is the key message as opposed to shunning what is not readily understood and appreciated. 



\section{POSITIVE LIVING STRATEGIES THAT CAN BE LEARNED FROM STUDIES ON NEAR-DEATH EXPERIENCES AND LIFE- THREATENING ILLNESSES}

\section{Madhu Kasiram, Penny Sartori}

\section{INTRODUCTION}

This paper explores how engagement with and "dialoguing with death" (Easwaran, 2008: Foreword) and serious illness may shape future living. It is based on researched evidence from two independent studies that, when compared, revealed remarkable comparative data relating to the subject of this paper. The first study was with patients in Swansea (UK) who had near-death experiences (NDEs), whilst the second was with women with AIDS, in Durban, South Africa. In both instances, the experiences of having a burdensome and life-long illness or a near-death experience were instrumental in prompting large-scale shifts in world view and personal life philosophy, which is what this paper examines. The paper also interrogates the connections across science, spirituality and health for the purpose of promoting learning and optimal services.

Although there is a research basis for most of the content of this article, there is also a philosophical component to this paper, which may not ordinarily be found in traditional scientific articles. This is because the authors believe that the subject of this paper resists being caged within a scientific paradigm, and so the authors will engage with literature on metaphysics and spirituality to foreground or background some of the findings.

\section{BACKGROUND AND CONTEXT}

What can confronting death and experiencing illness teach us about living? Said Easwaran (2008: Foreword) says: "We begin to take life seriously when we take death seriously. Otherwise, we run the risk of discovering, when we come to die, that we have never lived." Indeed, illness and near-death experience point many in the direction of finding new meanings about life and a new view of their place in the world (Fenwick, 2004) and can instigate a total re-evaluation of one's life (Groth-Marnat \& Summers, 1998).

These two research studies were unrelated to each other, originating from entirely different contexts and motivations for conducting the research.

Study 1 was motivated by the prolonged death of an intensive-care patient (Sartori, 2008) in Swansea, UK. Subsequently, the UK's first long-term prospective study of NDEs was undertaken at the intensive-care unit. NDEs are under-reported as patients do not understand them, yet they are profound (Moody, 1975; Ring, 1980; Sartori, 2008, 2014; Van Lommel, Van Wees, Meyers \& Eifferich, 2001), necessitating support in order to understand and integrate them into their lives. The aim of the study was multifaceted; it was intended to explore: 1) if NDEs could be explained by physiological factors such as abnormal blood results, drugs administered; 2) if NDEs were more prevalent in certain illnesses/circumstances; 3) if NDEs were hallucinations 4); if the out-of-body component often reported in NDEs could be verified; 5) if demographics 
influenced the reporting of an NDE; and 6) if there were any life changes after the NDE. This article reports on only those findings related to its topic, namely the changes experienced in patients after the experience.

Study 2 was motivated by an increased fear among South African women of their HIV status, debility and impending death (Kasiram, Ngcobo, Oliphant \& Roestenberg, 2013). The aim of the study was to understand the experiences of HIV-positive women and recommendations to them for continued living. This study, conducted in 2010, served as a springboard for several related research studies by one of the authors; for example, in 2011 a comparative analysis was undertaken of experiences of South African women with those in Texas, USA and later still (2012) a workshop was presented with South African service providers to identify service provision needs and gaps in respect of HIV and AIDS. Although data from the first study are reported and critically examined in this article, these other study results are also included as they were deemed necessary to illuminate the topic of this article and/or introduce new questions and concerns relating to the topic.

The question is: How are these two studies related to the topic of this article?

Patients in intensive care face the possibility of death (Sartori, 2008) and being "defeated" by their illness. Some of these patients reported remarkable spiritually transformative near-death experiences (NDEs) which influenced how they live their lives when they recover. Similarly, women with AIDS regard themselves as "condemned" to a life of shame, hopelessness, ill health and impending death (Ngcobo, 2011), aptly described by Das (2012:71) as being "damned and defeated", but whose lives are transformed by the experience and who live differently after a positive HIV diagnosis.

\section{RESEARCH METHOD}

\section{Study on NDEs}

The study on NDEs involved several phases, commencing with a quantitative study of over 300 intensive-care patients in a hospital in Swansea, UK, over a period of 5 years (1998 to 2003). Fifteen of these patients reported an NDE. Seven of the NDEs occurred during cardiac arrest, when there should have been no possibility of consciousness. Because of the patients' illness and death, it was possible to follow up only three of these patients after more than six months to establish any long-term changes. Interrogation of this sample of 15 who experienced an NDE and three of these patients who were followed up long term involved the use of qualitative methodologies, employing semi-structured interviews to glean rich detail. The article is based on the latter two qualitative components of the project.

\section{Study with HIV-positive women}

This study employed a qualitative paradigm, using exploratory and descriptive designs and purposive sampling to glean thick, rich descriptions (Terre blanche, Durrheim \& Painter, 2006) from respondents. 
In the study with HIV-positive women in South Africa (conducted in 2011) women attending the Family Therapy Clinic at the university where one of the authors is employed and were invited to share their stories of survival after HIV and AIDS. Although the final sample in this component of the study was only 7 , the rich detail in their stories offers an inside perspective of how these women negotiated the journey from diagnosis to positive future living.

The research instrument was the unstructured interview guide that identified core themes for exploration using language that suited the varying intellectual capacities of respondents whilst also allowing for further questioning/exploration.

The researcher/author used the narrative approach to yield data for this part of the study in order to appreciate the multifarious plots of their lived experiences (White, 1975). Since the women were primarily offering their stories for the research study because they were receiving therapeutic assistance, narrative therapy was the obvious choice of approach as it allowed for dominant discourses such as shame and blame to be "reauthored" and "re-framed" for future positive living.

Thematic content analysis was used in both studies. Although there were many variations in the experiences of patients and women, these were easily condensed into themes and subthemes. The results section of this article discusses these common and different experiences.

\section{ETHICAL CONSIDERATIONS}

Both studies involved very sensitive issues and the researchers had to be vigilant of the need to ensure no harm during data collection. Indeed, in both studies the researchers' roles were conflated with those of therapists/caregivers in order to address painful issues. "Attentiveness and responsiveness" (Hugman, 2010:158) were key to ensuring reliable data and they were painstakingly employed throughout data collection. On site referral was not necessary as the researchers themselves took responsibility to assist participants. In addition, because of the possibility of power imbalances between the researcher and participant, continuous or iterative informed consent (Hugman, 2010) was used throughout the research process to ensure that participants were fully knowledgeable about, and gave permission for, the research.

For both projects ethical clearance was granted by the University and Local Research Ethics Committee under whose auspices the studies were conducted.

\section{RESULTS AND DISCUSSION}

Both studies demonstrated just how life-transforming respondents' experiences were: positive living, being more compassionate and serving others were common themes pertinent to both studies.

Key differences were generally related to the intensity of their experiences and to patients in the NDE study having a heightened state of awareness and having no fear of death. The women in the HIV study, on the other hand, although having a renewed awareness pertaining to the gift of life, still feared their illness and impending death. 
These results/themes are discussed below. Although the authors carefully formulated these themes after data immersion (Terre blanche et al., 2006), there was a degree of overlap across the themes; this was regarded as inevitable, given the nature of the topic as one that pervades so many aspects of one's life.

\section{COMMUNICATING THE DIAGNOSIS/EXPERIENCE}

NDE patients are particularly affected by the disbelief encountered when communicating their experience to others (Kason, 2000; Sartori, 2014). Indeed, they even doubted their own sanity in the light of their own and other people's reactions. Research has shown that the knowledge of healthcare workers in understanding NDEs is severely limited and there is an over-estimation of their knowledge (Bucher et al., 1997, Fracasso, Friedman \& Young, 2010; Hayes \& Orne, 1990; Orne, 1986). The NDE is a transcendent experience with no other human experience to compare it to, making it almost impossible to explain using everyday language. They needed the help and support of professionals to come to terms with the experience. The concern is just how equipped medical and paramedical personnel may be to help in this capacity (Kasiram \& Sartori, 2014) in the face of such non-acceptance of NDEs.

In the HIV study women informed only those whom "they trusted" about their positive HIV status as fear of censure was commonplace. Sadly, service gaps abound in the area of support (Kasiram \& Beattie, 2014, in press). Both studies found that support when learning of one's diagnosis was limited, although the reasons for this differed somewhat, as explained earlier.

In addition to the psychological impact, there can also be physical changes. Many people who have undergone an NDE later made remarkable recoveries, sometimes even to the extent of being medically inexplicable (Sartori, 2014), as though the transcendent experience and the unconditional love they experienced during the near-death encounter healed them of the illness. This experience of recovery was not the case with all of the patients in the NDE study, some of whom died soon after the initial interview, although the case of Patient 10 demonstrated the inexplicable healing of a congenital abnormality (Sartori, Badham \& Fenwick, 2006). Such inexplicable recovery derived from an equally inexplicable NDE that typically defied logic and alienated patients from staff and even loved ones, who questioned their sanity at a time when they were most in need of comfort and support. "Recovery" in the shape of changing to live life more fully (discussed in the next theme) may be attributed to their close encounters with death. Indeed, both sets of participants often referred to "having a new lease on life" as a result of their experiences.

\section{FEAR AND LIVING LIFE FULLY}

Both studies showed that there was an unambiguous expression of changing one's life and life philosophy. In the NDE study a participant stated how there was now "no fear of death" and that there was "the need to live life fully". This philosophical change to becoming fearless and free to live optimally appears to have been triggered by the overwhelming unconditional love experienced and total dissolution of ego experienced during the altered state of consciousness. This state is often referred to as "realer than real" (Sartori, 2008, 
2014). When one experiences profound acceptance and love, there appears to be a concomitant release from feelings of guilt, blame and/or self-loathing that generates energy for future living (Walsh, 1995). This was also experienced by the women in the HIV/AIDS study, but to a lesser degree. These women received some measure of support and love from a few significant others, but this was not always viewed as unconditional as in the NDE study. It must be noted that the source of support for the women was essentially human rather than esoteric. Hence although the women discussed the need to live life more meaningfully, it is likely that this was brought about primarily because of wanting to maintain the love and support of their significant others. Fear of death and debility from the progression of the disease still dominated (Kasiram et al., 2013) as compared to in patients in the NDE study, who experienced an absence of fear about death.

\section{COPING}

Patients who had an NDE felt empowered by the experience and referred to having an "inner knowing" or "inner strength". They attributed this strength as emanating from the altered state of consciousness of the NDE and were able to tap into this memory for strength to live positively and cope in general. Their conviction based on this state of consciousness/knowing after the NDE was that they were accepted and loved unconditionally. They appreciated their mortality and were not afraid to die, resulting in their living life fully "in the moment" and "in the now". This aspect of being present to life and in awe of rather in fear of life is also mentioned as a typical characteristic of psychological changes experienced by NDEers (www.iands.org).

In comparison, women in the HIV and AIDS study continued to feel vulnerable even though they too relied on an inner strength (believed to be from God). They appreciated the fragility of their lives and also wanted to live life fully and to be "present". This difference in findings in the studies may be attributable to the women not receiving the same quality of support as received by the NDE patients and to the women's source of support being viewed as non-spiritual. All the women did lean God-ward for solace and comfort, and in many instances found this in their churches, where they were also offered material help. So, although they lived in the moment and were altruistic (see earlier theme), they seemed to do so out of fear of their impending death and making the most of what was left of their lives rather than because of experiencing first-hand the unconditional love and altered state of consciousness experienced by the NDE patients. It must also be noted that financial need and food insecurity were at the forefront of their concerns, and hence seeking comfort from the church may have been primarily motivated by material want.

The women worked hard at introducing change and a hopeful future into their lives. Examples of their efforts were prayer, meditation, engaging with nature (cf. Kasiram \& Oliphant, 2007) and performing ritualistic activities such as daily gardening, which provided a source of food at a time when there was no income or uncertainty over an income.

Other coping mechanisms adopted by women in the HIV and AIDS study included:

- Nurturing positive relationships as these promoted a healthy outlook and healing. Psychiatrist, Larry Culliford (2007) highlights the value of positive relationships, 
explaining that we all want to be loved and experience ourselves as loveable. Such relationships are not only healing, but also prevent judgmentalism, promote forgiveness and inspire support. Forgiveness is also discussed as one of the "aftereffects of NDEs" on the IANDS website (www.iands.org).

- Re-writing the "poor me" script from being condemned towards deserving kindness, forgiveness, love, support.

- Externalisation: to come to terms with their illness saying:

"I am bigger than AIDS, not AIDS."

"It is just a virus, not me."

This strategy was not as clearly evident in the NDE study, although it is possible that living life fully and being present was accompanied by a mind shift (a re-authoring of one's story) to not being only the illness but also a person deserving of a positive future. The likelihood is also that this finding is afforded individual attention because the HIV and AIDS study employed narrative therapy during data collection. In comparison the NDE study used an initial open unstructured interview, without the component of therapeutic influence, followed by a semi-structured interview.

\section{CHANGES IN VALUES}

Both sets of participants experienced changes to their values, particularly with regard to their relationships and in being altruistic.

In the NDE study, so profound was the experience that it changed relationship patterns between patients and their significant others in both positive and negative ways. In fact, previous research (Christian, 2006; Stout, Jacquin \& Atwater, 2006) has shown that some relationships after an NDE were re-evaluated and led to separation and divorce. One aspect of this is attributed by IANDS to NDErs being more openly generous, which is interpreted as "flirtatious disloyalty" (www.iands.org) by spouses and, if left unresolved, could culminate in divorce. However, in many instances the NDE helped patients "appreciate family and friends more". There was more time invested in these relationships and communication improved. However, considering the lack of support regarding the NDE experience itself (discussed earlier), it may be deduced that improved communication did not necessarily infiltrate the aspect of relationships.

In the HIV study, in the instances where relationships were toxic to begin with, the women actively disengaged from them. Where the relationship was trusted, the diagnosis strengthened communication and appreciation of the person/s. Several women in the study became community activists, communicating empowerment and self-care. Examples included talk shows on radio to alert people of risks of increased HIV infection; speaking with neighbours, teenagers and women to be vigilant about safe sex and reclaiming power in relationships; and "motivational talks" at formal or informal fora. These activities point to the need to fight prejudice (experienced by the women) associated with being HIV positive and leading these women to remedy the situation. Researchers agree that context and culturally relevant means that derive from personal experience (Coombe \& Kelly, 2001; James, Reddy, Ruiter, McCauley \& Den Borne, 
2006; Kelly, 2002; Visser, 2005) help hugely to address misconceptions around HIV and AIDS. Mulqueeny (2014), an HIV-positive postgraduate student, explains that becoming educationally involved not only addresses the problem of prejudice, but also the concomitant lack of support at a time when this is most needed.

However, not all the women in the study were able to look outside of their own pain (Rojano, 2004) and pursue the path of altruism. This finding is supported by other research concerning women's social and economic dependence on their male counterparts, placing them at greater psychosocial disadvantage and HIV risk (Dageid \& Duckert, 2008; Murphy \& Greenwell, 2006; Picasso, 2008). Thus it seems that where participants were trapped in poverty, they remained in toxic relationships, at the risk of re-infection, and were hardly able to feel positive enough to share their life lessons with others.

Altruism could stem from the feelings of unity and interconnectivity described by many who have had an NDE and of a "sisterhood" (Kasiram \& Sookoo, 2009) that drives people to care for and support one another. Rojano (2005) also discusses this in his community model of family therapy in describing the need to become civically engaged after one receives assistance, and progressing from receiving to giving as a citizen. It seems that in the case of persons experiencing near death or life-threatening illness, becoming civically engaged seems to require little or no coaxing.

\section{PARTICIPANT AND AUTHOR RECOMMENDATIONS}

In both studies participants were asked about recommendations for future living. These are discussed alongside additional recommendations by the authors.

In the HIV and AIDS study the women made very pragmatic suggestions. They wanted the government to actively address the burgeoning spread of AIDS in South Africa, this being successfully achieved as per the UNFPA (2014) report citing an overall 60\% reduction in HIV and AIDS rates in the country (UNFPA South Africa, 2014).

Since the major problem among the women was poverty and food insecurity, the twin injustices facing the nation (Kasiram, 2011), participants understandably requested more social security, particularly in helping them take care of their children and dependants. Alongside this request was one for assistance with transport costs in getting treatment and a one-stop centre or mobile units that allow easy access to all related services.

A further recommendation is to re-kindle interest in simple, do-able activities such as walks or gardening, as these clearly offered a sense of routine and normality, which illness and incapacity steal from a person. This may require creative effort, but is worth pursuing. Similarly, because connecting with others at a formal or informal level was viewed as healing, this requires dedicated attention. Electronic communication via mobile phones and the computer, using websites dedicated to the issue, would go a long way in linking people and in facilitating problem solving. With access to ecommunication being increasingly available and even affordable, this possibility needs further exploration and development. 
Being at the centre of services was also an expressed recommendation by women in the HIV and AIDS study. Health care workers emphasise "saving unborn babies" and portrayed the HIV-infected pregnant women as "time bombs" (Desgrees-du Lou \& Coleman, 2005). This comment is worrying given how long AIDS has been with us in South Africa, but it was also clearly expressed in the 2011 study by Ngcobo (2011) and therefore reflects how little has shifted attitudinally. Clearly such judgmentalism and side-lining of HIV positive women needs to change.

In the NDE study, making sense of the experience and receiving support were clearly expressed as a need. Thus, it is essential that NDEs are acknowledged by healthcare workers and family members in order to support patients during recovery. In this regard, Fenwick (2004:2) reports on the growth of "spiritual medicine" over the years, but believes that there is still much further to go. Science, spirituality and health do not seem to intersect in as ideal a fashion as the results of these studies suggest. NDEs clearly have the potential to empower patients for the rest of their lives; so profound is the experience that it can teach us all, without our having to come close to death, if we could engage with what these people are saying. It is recommended that NDEs and other end-of-life experiences be incorporated into the education of all healthcare workers (Sartori, 2014). It is also recommended that caring for patients should not be restricted to only the physical, but should also incorporate practices that acknowledge and address the spiritual needs of patients. If the mind is not healed then how can we expect the body to heal?

Engaging spiritually or outside of the box to make sense of profound experiences of serious illness and NDEs is important given the active side-lining of these experiences. Resisting the unknown is unhelpful and irresponsible for professionals in the caring sector. Professionals should not judge or shy away from people whose lived or neardeath experiences do not follow the laws of logic. To this end, professionals may need training or re-training.

Women in the study depended on and valued religious and spiritual support, pointing to the need to steer them in this direction. The profundity of the effects of the illness may drive this need and should not be avoided as a "no-go" area in professional service provision.

\section{CONCLUSION}

This article opens up a doorway for service professionals, educators and researchers to further engage with the topic, to more deliberately connect science, spirituality and health, and introduce spirituality into medicine (Fenwick, 2004).

Lessons for service professionals from this study point to the need to work with motivated and inspired survivors of HIV/AIDS, so that they may be supported in their efforts to educate and empower other women. They must be enabled to voice their very pragmatic suggestions to government for one-stop service centres and to other women to take charge of their sexual health. Service professionals should also note the power of the narrative approach in changing debilitating dominant discourses, so that people experiencing the pain and censure associated with illness or a near-death experience may be enabled to make sense of their experiences and lead more meaningful lives. Furthermore, since simple activities like ritual gardening and attending church proved 
meaningful and therapeutic to women in the study, service professionals need to encourage such activities alongside seeking and accessing more costly interventions.

In both studies the need for connection with others with similar experiences and then with the community at large was evident. Service professionals need to recognise the isolating effect of a near-death experience or life-threatening experience and ensure that support is offered to help with making sense of and dealing with the experience. The tendency is to disregard esoteric experience or ones where spiritual support is indicated, but we need to embrace this as real and engage accordingly.

There is long road to be travelled in offering truly holistic help in cases of near-death and life-threatening experiences. Let us travel this journey with commitment as caring professionals.

\section{REFERENCES}

BUCHER, L., WIMBUSH, F.B., HARDIE, T. \& HAYES, E.R. 1997. Near-death experiences: critical care nurses attitudes and interventions. Dimensions of Critical Care Nursing, 16(4):194-201.

CHRISTIAN, S.R. 2006. Marital satisfaction and stability following a near-death experience of one of the marital partners. Dissertation Abstracts International Section A: Humanities and Social Sciences, 66(11-A):3925.

COOMBE, C. \& KELLY, M.J. 2001. Education as a vehicle for combating HIV/AIDS. Prospects, XXXI(3):438-445.

CULLIFORD, L. 2007. Love, healing and happiness: spiritual wisdom for secular times. Winchester: UK. O Books.

DAGEID, W. \& DUCKERT, F. 2008. "Balancing between normality and social death", black, rural, South African women coping with HIV/AIDS. Qualitative Health Research, 18(182):182-195.

DESGREES-DU LOU, A. \& COLEMAN, H. 2005. The couple and HIV/AIDS in SubSaharan Africa: telling the partner, sexual activity and child-bearing. Population, 60(3):179-198.

DAS, G. 2012. The difficulty of being good. India: Penguin Books.

EASWARAN, E. 2008. Dialogue with Death. Mumbai: JAICO Publishing House.

FENWICK, P. 2004. Science and spirituality: a challenge for the $21^{\text {st }}$ century. [Online] Available: www.iands.org.research-articles/42-dr-fenwick-md-science.

[Accessed: 22/09/2014].

FRACASSO, C., FRIEDMAN, H. \& YOUNG, M.S. 2010. Psychologists' knowledge of and attitudes about near-death experiences: changes over time and relationship to transpersonal self-concept. Journal of Near-Death Studies, 29(1):273-281.

GROTH-MARNAT, G. \& SUMMERS, R. 1998. Altered beliefs, attitudes and behaviours following near-death experiences. Journal of Humanistic Psychology, 38(3):110-125. 
HAYES, E.R. \& ORNE, R.M. 1990. A study of the relationship between knowledge and attitudes of nurses in practice related to near-death experience. Loss, Grief and Care, 4(1-2):71-80.

HUGMAN, R. 2010. Social work research \& ethics. In: SHAW, I., BRIAR-LAWSON, K., ORME, J. \& RUCKDESCHEL, R. (eds) The Sage Handbook of Social Work Research. Thousand Oaks, London \& New Delhi: Sage Publications, 149-165.

IANDS (undated). www.iands.org. [Accessed: 22/09/2014].

JAMES, S., REDDY, P., RUITER, R.A.C., McCAULEY, A. \& DEN BORNE, B. 2006. The impact of an HIV and AIDS Life Skills Program on Secondary School Students in KwaZulu-Natal, South Africa. AIDS Education, 18(4):281-294.

KASIRAM, M. \& OLIPHANT, E. 2007. Indigenizing family therapy for South African use: challenges and changes. Journal of Family Psychotherapy, 18(2):71-82.

KASIRAM, M. \& SOOKOO, A. 2009. Belly dance: a strategy for female self care. Conference Presentation. WAPR. Lucknow, India.

KASIRAM, M. 2011. HIV/AIDS in sub Saharan Africa: theories and practice. Social Work Practitioner-Researcher, 23(2):171-189.

KASIRAM, M., NGCOBO, N., OLIPHANT, E. \& ROESTENBERG, W. 2013. HIV/AIDS and women: African and South African perspectives. Indilinga African Journal of Indigenous Knowledge Systems : Revisiting the Research Paradigm, 12(1):62-79.

KASIRAM, M. \& SARTORI, P. 2014. Near death experience: teaching, learning and therapy for positive living. Conference presentation at APPAC, Athens, May 2014.

KASIRAM, M. \& BEATTIE, K. 2014 (in press). Service needs of HIV positive persons: a South African perspective. Article accepted for printing in Journal of Family Psychotherapy.

KASON, Y. 2000. Farther shores: exploring how near-death, Kundalini and mystical experiences can transform our ordinary lives. Ontario: Harper Collins Publishers Ltd.

KELLY, M. 2002. Standing education on its head: aspects of schooling in a world with HIV/AIDS. Current Issues in Comparative Education, 3(1):28-38.

MOODY, R. 1975. Life after life. USA: Bantham Books.

MULQUEENY, D. 2014. Lecture notes to level 4 social work students. University of KwaZulu-Natal, South Africa.

MURPHY, D.A. \& GREENWELL, L. 2006. Correlates of HIV-related stigma among HIV positive mothers and their uninfected adolescent children. Women and Health, 44:19-44.

NGCOBO, N.P. 2011. Exploring the narratives of women with HIV/AIDS in a designated health setting. Durban: University of KwaZulu-Natal. (Unpublished MA Thesis)

ORNE, R.M. 1986. Nurse's views of NDEs. American Journal of Nursing, 86:419-20. 
PICASSO, N. 2008. Interpreting VAW from the experiences of women living with HIV/AIDS. In: CONNECTION, D. (ed) The multiple face of the intersections between HIV and Violence Against Women. Washington DC: Development Connections (DVCN), 22-27.

RING, K. 1980. Life at death: a scientific investigation of the near-death experience. New York: Coward, McCann and Geoghegan.

ROJANO, R. 2005. The practice of community family therapy. Family Process, 43(1):59-78.

SARTORI, P. 2008. The near-death experiences of hospitalized intensive care patients: a five year clinical study. Lampeter, Queenstown, New York: The Edwin Mellen Press.

SARTORI, P., BADHAM, P. \& FENWICK, P. 2006. A prospectively studied neardeath experience with corroborated out-of-body perceptions and unexplained healing. Journal of Near-Death Studies, 25(2):69-84.

SARTORI, P. 2014. The wisdom of near-death experiences: how understanding NDEs can help us live more fully. London: Watkins Publishing Limited.

STOUT, Y.M., JACQUIN, L.A. \& ATWATER, P.M.H. 2006. Six major challenges faced by near-death experiencers. Journal of Near-Death Studies, 25(1):49-62.

TERRE BLANCHE, M., DURRHEIM, K. \& PAINTER, D. (eds) 2006. Research in practice. Applied methods for the social sciences $\left(2^{\text {nd }}\right.$ ed $)$. Cape Town: University of Cape Town Press.

UNFPA SOUTH AFRICA. 2014. [Online] Available: http://countryoffice.unfpa.org/ southafrica/2013/05/03/6675/hiv [Accessed: 29/09/2014].

VAN LOMMEL, P., VAN WEES, R., MEYERS, V. \& EIFFERICH, I. 2001. Neardeath experience in survivors of cardiac arrest: a prospective study in the Netherlands. The Lancet, 358:2039-2045.

VISSER, M.J. 2005. Life skills training as HIV/AIDS preventive strategy in secondary schools: evaluation of a large-scale implementation process. Journal des Aspects Sociaux du VIH/SIDA, 2(1):203-216.

WALSH, N.D. 1995. Conversations with God. Book 1. Great Britain: Hodder and Stoughton.

WHITE, M. 1995. Re-Authoring Lives. Adelaide, Australia: Dulwich Centre Publications.

Prof Madhu Kasiram, Social Work Lecturer, University of KwaZulu-Natal, South Africa; Dr Penny Sartori, Lecturer, Department of Continuing Adult Education, University of Swansea, Wales, United Kingdom. 